\title{
Héroes, rituales y culto: la tragedia y el caso de Hipólito ${ }^{1}$
}

\author{
Lidia Gambon \\ Universidad Nacional del Sur, Argentina \\ lgambon@uns.edu.ar
}

Heroes, Rituals and Worship: Tragedy and Hippolytus' Case

\begin{abstract}
Resumen:
Aunque, al igual que sucede con otros héroes griegos, Hipólito no fue únicamente una figura del mito, sino también del culto, esta relación muestra importantes aspectos discordantes. Nos proponemos, en el presente artículo, puntualizar estas discordancias, centrándonos en tres puntos significativos del tratamiento trágico (la localización de la historia, el nombre del personaje y la relación del héroe con la divinidad de culto). Con ello procuramos destacar que Hipólito, una figura de culto eminente en Trecén, fue en Atenas esencialmente un héroe trágico, y orientar nuestras conclusiones hacia la importancia que para ello tuvo un aspecto que Eurípides remarcó en Hipólito (la única tragedia completa conservada): la tensión y complementariedad entre Afrodita y Ártemis.
\end{abstract}

Palabras clave: Hipólito, Héroe, Culto, Tragedia.

\begin{abstract}
:
Although, like other Greek heroes, Hippolytus was not only a figure of myth, but also of cult, this relationship shows important discordant aspects. The aim of this paper is to clarify these aspects, focusing on three significant points of the tragic treatment (the events location, the name of the character, the hero's relationship with the cult divinity,). With this we try to highlight that Hippolytus - an eminent cult figure in Troezen - was essentially a tragic hero in Athens, and to conclude the importance of an aspect remarked by Euripides in his Hippolytus (the only complete tragedy preserved): the tension and complementarity between Aphrodite and Artemis.
\end{abstract}

KEYWORDs: Hippolytus, Hero, Worship, Tragedy.

Aunque los héroes míticos resultan más conocidos por su trascendencia literaria, no caben dudas de sus conexiones religiosas y de su importancia en los cultos griegos, incluso cuando estas conexiones resulten para los estudiosos difíciles de armonizar. Hipólito constituye, sin duda, un caso singular, por la disociación de su figura con algunos aspectos del culto que continúan planteando interrogantes no resueltos. En este sentido, y considerando la trascendencia del personaje dramático, se entiende que Barrett (1964) se viera precisamente llevado a destacar, en la introducción a su canónica edición comentada, que la figura de Hipólito no fue solo una figura del mito, sino del culto (p. 3). Tal como sucedía con los otros héroes, el hijo de Teseo, según sabemos, fue objeto de veneración en Trecén y en el Ática, pero sobre todo entre los trecenios, quienes, al decir de Pausanias, eran especialmente afectos a los cultos locales. ${ }^{2}$ No obstante (y a pesar de la tendencia de Atenas a adoptar héroes trágicos, como Heracles enloquecido, o Áyax), los orígenes del culto de Hipólito resultan poco conocidos, y no se hallan en esa pólis ni parecen haber tenido su epicentro en ella. Y así, mientras el culto de Trecén, según testimonian las fuentes postclásicas, fue importante, el ático (pese a la relevancia del personaje mítico en el drama) careció de esta significatividad. Nos proponemos, en el presente artículo, trazar aquellos que consideramos los puntos nodales de estas discordancias, los que hicieron de Hipólito una figura de culto eminente en Trecén, y en Atenas, en cambio, una figura de "cuño" dramático. Ello con la intención de orientar nuestras conclusiones hacia el rol decisivo que en la vital relación dialógica entre tragedia y ritual 
pudo ocupar, a nuestro juicio, el énfasis en la tensión y complementariedad cúltica de Afrodita y Ártemis, que Eurípides remarcó en su drama.

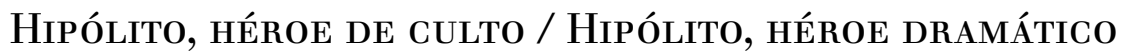

El culto de Hipólito en Trecén y el ritual que se le asocia es mencionado ya por Eurípides al final de su Hipólito (vv. 1423 ss.), y, con posterioridad, por Pausanias, quien habla de un templo muy famoso, una antigua estatua, un sacerdocio y sacrificios que, según la tradición local, habían sido establecidos en honor del héroe por Diomedes ya en tiempos micénicos:

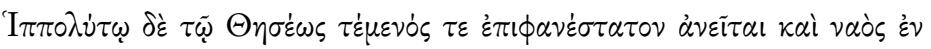

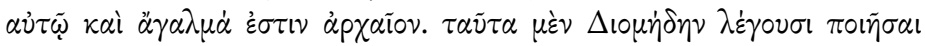

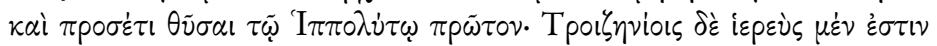

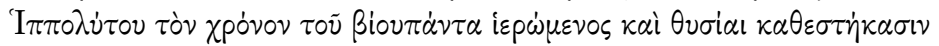

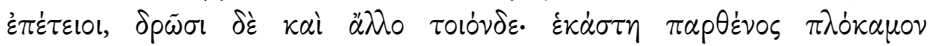

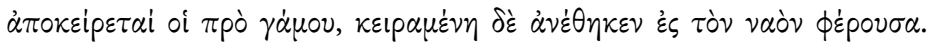

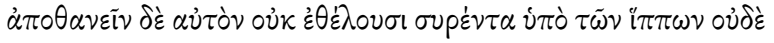

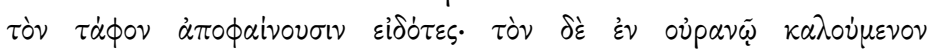

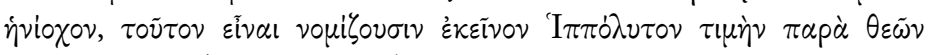

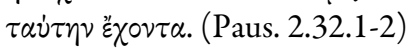

\begin{abstract}
A Hipólito, hijo de Teseo, está dedicado un recinto sagrado muy famoso, y en él hay un templo y una imagen antigua. Dicen que estas cosas las hizo Diomedes y que, además, él fue el primero que hizo sacrificios a Hipólito. Los de Trecén tienen un sacerdote de Hipólito que ejerce su función durante toda su vida y se han instituido sacrificios anuales; también hacen lo siguiente: cada muchacha se corta un mechón antes de la boda, y una vez cortado lo lleva al templo y lo ofrenda en él. No quieren admitir que Hipólito murió arrastrado por los caballos ni muestran, aunque la conocen, su tumba. Consideran que la constelación celeste Auriga es aquel Hipólito que ha recibido de los dioses este honor.
\end{abstract}

Pausanias (2.32.4) menciona también la existencia de una tumba $(\mu \nu \tilde{\eta} \mu \alpha)$ de Hipólito, no muy distante de la de Fedra, y seguramente ligada, en su origen, al culto de estas figuras semidivinas; como todos los cultos de este tipo, el de Hipólito poseería un carácter eminentemente ctónico, centrado en la potencia viviente del héroe tras la muerte. Tanto Eurípides como Pausanias aluden a la ofrenda de cabellos que las jóvenes núbiles antes del matrimonio le brindaban en el lugar, en un rito que honraba a un héroe venerado especialmente

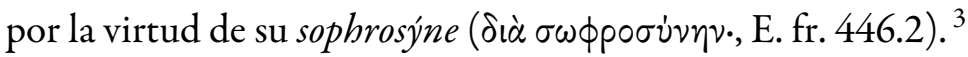

Respecto del culto ático de Hipólito, es Pausanias también quien refiere a la existencia de un monumento sepulcral, situado delante del templo de Témis, en la ladera sur de la Acrópolis (1.22); no obstante lo tardío de esta fuente, la existencia de un recinto de veneración de Hipólito y de un culto en su honor en Atenas se encuentran atestiguados epigráficamente por primera vez ya en época cercana a la tragedia conservada. ${ }^{4}$ No sabemos, pues, cuándo se estableció el culto de Hipólito allí, pero es dable suponer que, junto con el territorio argivo que dominaron al NE del Peloponeso, los atenienses también adoptaron oportunamente el culto al héroe de Trecén. Por otra parte, la estrecha relación entre el culto de Hipólito y la diosa Afrodita y algunos hallazgos arqueológicos de época micénica plantearon la búsqueda de una explicación para la adopción de dicho culto, así como para su fuerte conexión con esta divinidad, y no con Ártemis, a la que lo uniría el drama ático.

Efectivamente, uno de los rasgos más interesantes de ambos cultos (el ático y el trecenio), como declaraba oportunamente Barrett (1964, p. 5), es que el culto de Hipólito en cada caso está asociado a otros cultos divinos, aunque ninguno de ellos se relaciona estrictamente con la hermana de Apolo. Por un lado, y como el prólogo mismo de la tragedia euripidea evoca, se vincula al culto de Afrodita: en Trecén, se trata del culto

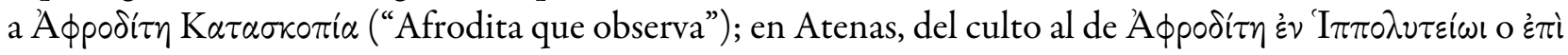
I $\pi \pi 0 \lambda v i \tau \omega$ (E. Hipp., vv. 32-33). ${ }^{5}$ Por otro, el culto de Hipólito se vincula al culto de Asclepio, divinidad sanadora de advenimiento más tardío, cuyas conexiones con el héroe no resultan demasiado claras y parecen anclar en la versión épica precedente del mito. ${ }^{6}$ 
Dejando de lado, sin embargo, estos precedentes épicos, sabemos que el personaje del hijo de Teseo fue tema de tres dramas griegos, dos de Eurípides, Hipólito I (o Hipólito velado), e Hipólito II (o Hipólito coronado), y uno de Sófocles, titulado Fedra. De la datación (y conexión) de dichos dramas, poco puede afirmarse con certeza, excepto que la única versión supérstite - Hipólito II- es del 428 a.C.; y (lo que es más importante) que en las tres versiones dramáticas por vez primera la historia de Hipólito y Teseo se pone en relación conjuntamente con la de Fedra. ${ }^{7}$ En los aspectos que ofrecen más certidumbres y puntos en común, las tres tramas dramáticas incluyen — como señala Sommerstein (2005, pp. 169-170) al menos cuatro secuencias coincidentes (aunque no en idéntico orden): a) Fedra, enamorada de su hijastro y rechazada por Hipólito, lo acusa de seducción; b) Teseo maldice a Hipólito y este muere; c) la verdad acerca de la pasión de Fedra es revelada a Teseo; d) Fedra se suicida. Es posible, a juzgar por el título - y con los reparos que esta conjetura supone- que la obra sofoclea se centrara fundamentalmente en el carácter de Fedra, y no de Hipólito, de cuyo tratamiento en el drama poco o nada sabemos a partir de los escasos versos conservados. ${ }^{8}$

Sin pretender adentrarnos en el camino sinuoso de los dramas perdidos, de su reconstrucción y de las innovaciones que plantearían respecto del que ha sobrevivido, la cuestión del culto del héroe, formulada en términos etiológicos, se relaciona inevitablemente con ello y se vincula estructural y predominantemente con la resolución del éxodo dramático de las piezas. A priori, lo que es posible afirmar con certeza es que mientras en ambos dramas de Eurípides esta relación etiológica con el culto del héroe está testimoniada, en Sófocles nos hallamos frente a la falta de evidencia textual; a partir de ello, y de las conexiones de este poeta con la introducción del culto a Asclepio en Atenas (c. 421/20 a.C.), las hipótesis se han centrado en las relaciones con esta divinidad en Fedra, su intervención final milagrosa para resucitar a Hipólito y proveer así una suerte de consolación por su injusta muerte. No obstante, la falta de testimonios (tanto del protagonismo de Hipólito como de la instauración de un culto) constituye una clara limitación en el caso de Sófocles. En todo caso, el hecho significativo (o los puntos significativos) de la relación discordante entre Hipólito como héroe mítico y como héroe de culto se centran en algunos aspectos que consideramos relevantes puntualizar aquí: el que refiere a la localización de la historia en Trecén o Atenas (I); el que refiere al nombre del personaje y su conexión con otros personajes míticos, Teseo y Fedra (II); el que refiere a la relación del héroe con la divinidad de culto (III).

\section{Trecén, un ESPACiO SIGNIFICATIVO}

Trecén (o Trocén), comarca y ciudad donde había reinado Piteo, abuelo de Teseo y antepasado de Hipólito, está situada en el Peloponeso, frente al territorio del Ática, y a través del Golfo Sarónico, al sudoeste de Atenas. La tumba del héroe, como se dijo, se le asociaba en la Antigüedad; y Barrett (1964, pp. 6-10) asegura que este fue el lugar de origen del mito de Hipólito, a juzgar por las implicancias de la referencia al espacio de muerte del héroe, causada por la aparición de un toro desde el mar. ${ }^{9}$ Desde Trecén el mito fue posteriormente adoptado por Atenas, hacia el s. VI a.C. con probabilidad, y en asociación con la emergencia de Teseo como héroe nacional. Hasta aquí culto y mito.

Trecén es el escenario de Hipólito II, aunque no ciertamente el de las fuentes latinas posteriores, que debieron seguir otra tradición, con toda probabilidad igualmente antigua. ${ }^{10}$ Las fuentes romanas, que sitúan la acción en Atenas, han ejercido influjo en la reconstrucción de la tragedia y la localización de Hipólito I, aun cuando hay coincidencia de la crítica en que esta era más bien la localización del drama de Sófocles. Sobre la localización de Hipólito $I$, a su vez, el influjo de dos testimonios papiráceos de la Hipótesis (P. Mich. 6222A y $P$. Oxy. 4620), en uno de los cuales se lee claramente el nombre de Trecén ( $P$. de Mich. 6222A, test. iib fr. C), aporta sustento a la localización del drama en Trecén, a pesar de los problemas que, por otro lado, los papiros plantean en relación con el apoyo en la tradición mitográfica para la reconstrucción de la trama que proponen. ${ }^{11}$ 
En cualquier caso, conviene destacar que la localización en Trecén, al parecer preferida por Eurípides, viene a confirmar en el drama la marginalidad que impone a Hipólito su bastardía. ${ }^{12}$ Ello no solo por su propia condición (hijo de Teseo y de una Amazona), sino en virtud de reforzar a través de su padre, el rey ateniense, las fuertes conexiones genealógicas con ese espacio: fue en Trecén donde nació Teseo, y su ascendencia materna de hijo bastardo se vincula al lugar (Teseo es hijo de Etra, hija, a su vez, del rey de Trecén, Piteo). ${ }^{13}$

Por ello, si bien la paternidad de Egeo - que testimonia la tradición mitográfica y el drama euripideo no ignora (cf. E. Hipp., vv. 1283-1284, 1431) - refuerza los vínculos de Teseo con Atenas, el drama conservado busca conjugarlo con la tradición local; y al subsumirlos, contribuye a focalizar y afianzar la importancia del tema de la bastardía en la obra, en sus alcances familiares sobre todo (más que en sus alcances políticos). ${ }^{14}$

Así, Eurípides recupera, junto a la paternidad ateniense de Egeo, la paternidad trecenia de Poseidón en la invocación de las maldiciones de Teseo a su hijo. Ello le permite reforzar, por un lado, la bastardía de Teseo, hecho que iguala su condición con la de Hipólito; por otro, parece recuperar, al mismo tiempo, una paternidad más ligada al culto y al héroe del culto que al del mito (la deidad principal de Trecén es Poseidón). A partir de allí, de esta relación más estrecha con el culto, reafirma también Teseo una paternidad capaz de operar con la eficacia que el carácter performativo de la maldición invocada requiere. ${ }^{15}$

Sin embargo, y a pesar de la importancia de Trecén en la configuración de Hipólito como figura marginal, es justo decir que los dos espacios (Atenas y Trecén) se juegan con paridad de relevancia en la obra conservada de Eurípides, hecho ligado a la bastardía de Hipólito. Así, en esta pieza, la ubicación de los sucesos en Trecén necesitó de la presencia previa de Hipólito en Atenas, a donde el hijo de Teseo habría ido para celebrar los augustos misterios de la tierra de Pandión (Hipp., v. 24). Con posterioridad, el exilio de Teseo, tras el crimen de los Palántidas, obligó a la convivencia de la esposa enamorada con el hijo bastardo de su esposo, circunscribiendo a los lindes mismos del ô̂kos el llamado "motivo de Putifar" y los riesgos de la marginal posición de Hipólito en términos vinculares y espaciales. ${ }^{16}$

La marginalidad de Hipólito, por otra parte, se reafirma en el drama con el castigo del exilio paterno. En esa escena Barrett ha remarcado las principales inconsistencias espaciales. Aunque en rigor Hipólito es exiliado no solo de Trecén sino de todos los dominios gobernados por su padre (vv. 973-975), Atenas epitomiza el extremo castigo: es la tierra a donde no puede ir, porque es la tierra fundada por los dioses, el espacio sagrado por excelencia. Es sobre todo de Atenas que Hipólito se siente desterrado (vv. 1093-1094). Y aunque el héroe yuxtapone en su saludo de despedida ambos espacios (Trecén y Atenas), su primer adiós es para la tierra de

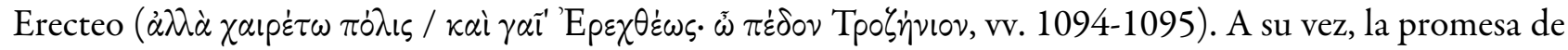
Ártemis de compensación por su sufrimiento tras la muerte implica los más grandes honores rituales en Trecén (v. 1424). Sin embargo, la última referencia espacial con que cierra el drama, en boca de Teseo, remite a la futura pérdida que implica la muerte de Hipólito, y es una exhortación casi "parabática" dirigida a los

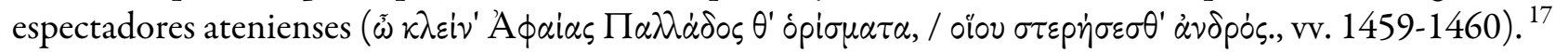

En síntesis, la localización en Trecén no resta peso a la ciudad del drama, Atenas, presente repetidamente en la obra, desde el prólogo al éxodo, al menos en el único drama completo conservado.

\section{El NOMBRE DE Hipólito}

El nombre del hijo de Teseo, desde su etimología, expresa la relación con el mundo equino (ï $\pi \pi \circ$ : "caballo"). Junto a la posibilidad de que dicho nombre pudiera derivarse, como destaca Halleran (1991, p. 117), del nombre de la madre - la Amazona Hipólita, y que esta filiación materna pudiera ser una innovación ática, se afirma con él (en él) especialmente la imagen de un héroe que mantiene estrechos vínculos con los caballos. ${ }^{18}$

Ello lleva a su asociación con Poseidón, divinidad que en términos de culto guarda particular vínculo con aquel animal y con los carros. ${ }^{19}$ Hasta aquí, pues, la relación entre el nombre del héroe mítico y el del culto: 
Hippolytus leaves little trace of any sort before the fifth century. His very name is elusive. It suggests something about horses and loosing, and may very well refer to the circumstances of his death - "loosed by horses". (Halleran, 2001, p. xxi)

Así, la asociación con Poseidón, los caballos y el carro están presentes fuertemente en la configuración de la muerte del héroe; ${ }^{20}$ pero en el drama conservado se derivan asimismo de la afinidad de Hipólito con Ártemis, de cuya compañía el joven efebo se complace (vv. 15-16), y a la que se asocian igualmente los caballos. Esta afinidad aparece especialmente remarcada en la pieza. La autodefinición de Hipólito como "cazador y siervo

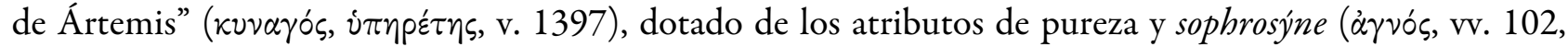

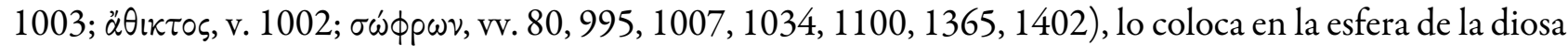
(de veneración de la diosa), junto con el grupo de cazadores y efebos que lo acompañan. Y como demuestra el himno a Ártemis que Hipólito entona al ingresar a escena (vv. 58-72), esta diosa y el mundo materno de las Amazonas tienen mucho en común, en su vínculo con los caballos y la caza, y con la vida en un estadio natural, pre-político, fuera del matrimonio.

Mención particular merece en este punto las consideraciones que surgen del título de las piezas dramáticas, ya que debemos tener en cuenta que del nombre del héroe o directamente vinculado a él se derivan los títulos de las obras (al menos de las dos obras de Eurípides, que, en contraste con la de Sófocles, recibieron el nombre del protagonista masculino). Las fuentes postclásicas refieren al Hipólito I con el título de Hipólito

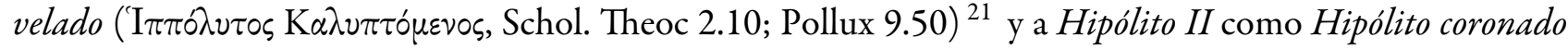

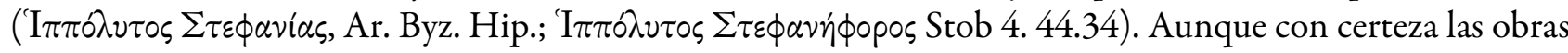
referidas a un mismo personaje mítico recibieron sus epítetos distintivos en el período helenístico, y en un tiempo seguramente anterior a Aristófanes de Bizancio, no puede ignorarse la significatividad del epíteto del Hipólito que ha llegado a nosotros, ya que refiere a una acción cultual específica: la que tiene lugar con el ingreso de Hipólito al inicio de la pieza, cuando ofrece a Ártemis, como don y expresión de su veneración, una corona (Hipp., vv. 82-83). ${ }^{22}$

Los aspectos señalados nos ponen frente a la relevancia concedida a Ártemis en la pieza conservada e introducen el tercer punto en que se sustenta nuestra argumentación.

\section{Hipólito, Ártemis y AFrodita}

Como señalamos, el héroe del culto aparece vinculado a la divinidad Afrodita (en Trecén y en Atenas) pero el héroe del drama (el recuerdo y la veneración del héroe del drama), excluyendo la posible vinculación a Asclepio en Fedra, se relaciona de modo explícito tanto con Afrodita como con Ártemis. ${ }^{23}$ Esta circunstancia, fuertemente explicitada en la tragedia euripidea supérstite, ha llevado a Francis Dunn a reforzar la idea de una simetría formal en la pieza, que vuelve a estas dos divinidades, en su cuidado equilibrio, igualmente relevantes, afirmando y definiendo un modelo de repetición que colapsa y anula las diferencias entre ellas y entre los protagonistas. ${ }^{24} \mathrm{Y}$ aunque poco pueda afirmarse acerca de la otra tragedia perdida de Eurípides sobre la base de los escasos fragmentos existentes, ninguna de estos contiene, como tampoco la tragedia sofoclea, referencias explícitas a Ártemis, lo que puede afirmarse como un aspecto singular del drama conservado, que contribuye fuertemente a su sentido, y que constituye uno de los puntos sustanciales de diferencia con el héroe del culto. ${ }^{25}$

Las epifanías divinas otorgan al prólogo y la escena final del éxodo de Hipólito (II), como sostuvo Sourvinou-Inwood (2004, p. 326) un carácter fuertemente religioso, centrado en la importancia del culto en la relación entre dioses y mortales, hecho que concede al ritual una densidad significativa que alcanza a toda la obra. ${ }^{26}$ Es obvio, pues, que la tragedia define sus propias reglas de relación con el ritual, y que estas, en Eurípides, no necesariamente han de limitar su significación etiológica a la escena final. Así, el prólogo coloca el ritual (o la ausencia de rituales de veneración a una diosa) como causa misma de la venganza divina contra 
Hipólito (vv. 10-13); ${ }^{27}$ a su vez, la pasión de Fedra está en el origen mismo de la fundación del templo en honor de Cipris:

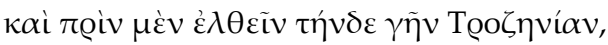

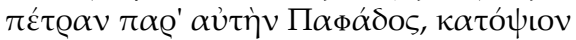

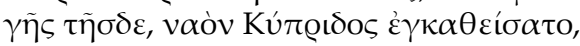

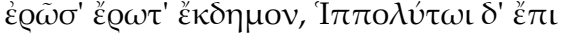

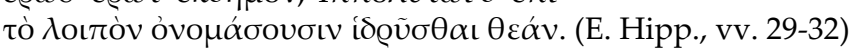

Afrodita: $Y$ antes de llegar a esta tierra de Trecén, junto a la misma piedra de Palas, visible desde esta tierra, estableció el templo de Cipris, enamorada de un amor ausente. Y al fundarlo, por Hipólito en el futuro llamarán a la diosa.

Y tal como Ártemis al final refiere al culto de Hipólito en Trecén, Afrodita, al comienzo, alude al culto de Hipólito en Atenas. Nos hallamos, pues, frente a una doble etiología, que no solo provee el vínculo con dos divinidades diferentes y antagónicas, sino que plantea una singularidad dramática. En efecto, aunque la etiología final es una característica idiosincrásica del drama euripideo, Hipólito (II) es la única de las tragedias completas con una etiología al comienzo y otra al final. ${ }^{28}$ Más allá de estas explicaciones etiológicas, la presencia de ambas diosas está perfectamente balanceada en la obra, ya que, además de las epifanías del prólogo y el éxodo, se patentiza en los himnos celebratorios y en la materializada memoria que representan visualmente estatuas y altares, aspectos todos que refuerzan la significatividad del ritual al interior de la pieza. ${ }^{29}$

Precisamente, la entrada de Hipólito inicia en sentido propio el desarrollo del drama con una acción de culto, enmarcada por una comitiva en procesión, himnos y ofrendas a Ártemis. Este marco ritual performativo solo refuerza el desbalance y el alejamiento de Hipólito de Afrodita, a quien el héroe desdeña (v. 113), pero cuya potestad es reconocida por todos los otros personajes (vv. 114-120; 522-524; 725-727; 1461). Y mientras en la caracterización de Fedra, el desdén por el culto a Díctina/Ártemis se integra solo a las hipótesis no confirmadas del Coro (vv. 145-147), y Fedra (bien que en su delirio) puede invocar a Ártemis (v. 228), no sucede claramente lo mismo con Afrodita en el caso del hijo de Teseo, ya que es el único que la menosprecia y la ignora (v. 12). ${ }^{30}$

La institución final del ritual anunciada por Ártemis en la tragedia deviene una forma de compensación a

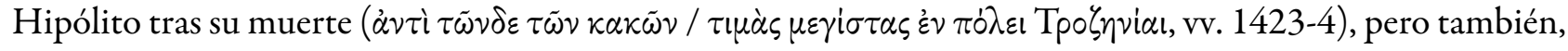
una forma de integrar esta figura marginal al espacio de la pólis:

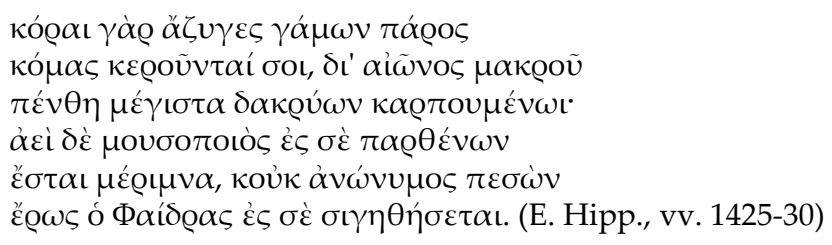

Ártemis: Las doncellas, antes de uncirse al yugo del matrimonio, cortarán sus cabellos para ti, y durante mucho tiempo tendrás el Džuto del gran dolor de sus lágrimas. Siempre para ti estará dedicada su musa, y el amor de Fedra por ti no será silenciado, cayendo en el olvido.

Esta integración solo es posible a través del ritual; en él, y por él, Hipólito, exiliado, un héroe que rechaza el matrimonio, reingresa de modo permanente al espacio de Trecén, y a la memoria de los atenienses, asociando parthenía y éros, su nombre y el de Fedra. El ritual al que alude Ártemis, el ritual que integra la transición 
de las doncellas al matrimonio, integra la tensión y la complementariedad de las dos divinidades, Afrodita y Ártemis, de cuyo balance y equilibrio depende la supervivencia de la pólis.

$\mathrm{Al}$ abordar un tema (ritual), un héroe (Hipólito) y un género (tragedia) como el que nos ocuparon aquí, parece inevitable la referencia a la discusión que ha sido el centro de la crítica, i.e. la tragedia y la invención de la etiología, en especial cuando el autor del que depende nuestra principal fuente antigua es Eurípides. Sin embargo, y sin discutir su relevancia, el caso de Hipólito parece desautorizar a priori la hipótesis de una invención etiológica con fines únicamente literarios, y es posible coincidir con Ebbott (2017) cuando afirma con relación a este punto que "we cannot prove that the absence of other confirming evidence indicates fabrication” (p. 118). ${ }^{31} \mathrm{Al}$ mismo tiempo, el ejemplo de Hipólito desplaza los interrogantes, como hemos intentado hacer, hacia aquellos puntos que permiten puntualizar las discordancias entre un héroe mítico de cuna esencialmente dramática y el héroe del culto.

El punto sobre el que se potenció en Atenas la significatividad del héroe dramático giró en torno a la tensión y complementariedad de Afrodita y Ártemis en relación al matrimonio. Así, en la versión euripidea conservada (y ella es nuestro único testimonio trágico completo), el epicentro dramático está construido en torno a una doble etiología (al comienzo y al final de la pieza: la primera vinculada a Afrodita, la segunda a Ártemis). Esta doble etiología converge en torno a un eje: el de una polarizada visión de los roles genéricos en la que, a la par que se afirman los peligros de una sexualidad no controlada (como la que subyace tras el deseo de Fedra), se afirman también los de una sexualidad negada (como la de Hipólito). De ahí que el matrimonio esté en el centro mismo del drama, como mecanismo de regulación social y como instancia de pasaje a la que se concede especial relevancia. Todo el drama se arquitectura en torno a él, y se clausura con el ritual que se le asocia, un ritual que marca la transición, que evoca la pérdida que conlleva para las doncellas, a la par que se instituye en la perpetuación del recuerdo de las consecuencias para quien, como Hipólito, se niega a él.

Una cuidada sintaxis dramática, fundada en una concatenación de simetrías y contrastes (que la crítica ha señalado), y anclada en los puntos abordados, permitió a Eurípides reforzar, en la nueva presentación del mito, la tensión y complementariedad entre dos diosas que el héroe del culto no ponía necesariamente en relación. Y este aspecto, que venía a alinearse con la tensión como rasgo esencial de la tragedia, y con su carácter de institución social, en los términos en que la definiera Vernant (Vernant y Vidal-Naquet, 1972), dio en Atenas primacía al héroe en su identidad trágica.

\section{REFERENCIAS}

Barrett, W. S. (Ed.) (1964). Euripides. Hippolytos. Oxford: OUP.

Collard, C. y Cropp, M. J. (Eds.) (2008). Euripides: Fragments, VII.1, Aegeus-Meleager, LCL. Cambridge, MA: Harvard University Press.

Diggle, J. (Ed.) (1982-94). Euripidis. Fabulae, I-III. Oxford: OUP.

Halleran, M. R. (Ed.) (1995). Euripides. Hippolytus (trans. \& comm.). Warminster: Aris \& Phillips.

Halleran, M. R. (2001). Euripides. Hippolytus, Translation with Notes, Introduction and Essay. Newburyport, MA: Focus Pub.

Hamilton, R. (1982). Euripides' Hippolytus. Bryn Mawr, PA: Thomas Library.

Jouan, F. y van Looy, H. (Eds.) (1998-2003). Euripide. Tragédies. Fragments. T. VIII (1ere- 4ème partie). Paris: Les Belles Lettres.

Kannicht, R. (Ed.) (2004). Tragicorum Graecorum Fragmenta, vol. 5. Göttingen: Vandenhoek and Ruprecht.

SommersteinA. H., Fitzpatrick, D. y Talboy, T. (Eds.)(2006). Sophocles: Selected Fragmentary Plays, Volume I. Oxford: Oxbow Books.

Spiro, F. (Ed.) (1967). Pausaniae Graeciae descriptio. Stuttgart: B. G. Teubner. 
Thesaurus Linguae Graecae.TLG.: a digital library of Greek literature, Irvine, CA. Versión E [CD ROM], University of California, 2000. Actualizaciones posteriores disponibles en: http://www.tlg.uci.edu/authors/post_tlg_e.php.

\section{Bibliografía CRÍtiCA GENERAL}

Bañuls, J. V. y Crespo, P. (2008). La Fedra de Sófocles. En A. Pociña y A. López (Eds.), Fedras de ayer y de hoy. Teatro, poesia, narrativa y cine ante un mito clásico (pp. 15-83). Granada: Universidad de Granada.

Bastianini, G. y Casanova, A. (Eds.) (2005). Euripide e i Papiri. Atti del Convegno Internazionale di Studi Firenze, 10-11 Giugno 2004. Firenze: Istituto Papirologico "G. Vitelli”.

Burkert, W. (2007 [1977]). Religión griega arcaica y clásica, trad. H. Bernabé. Madrid: Abada Editores.

Casanova, A. (2014). La recente Hypothesis e la prima uccisione nell'Ippolito I di Euripide (con due considerazioni sul titolo). En A. Pérez Jiménez (Ed.), Realidad, fantasia, interpretación, fimciones y pervivencia de lmito griego. Estudios en honor del Profesor Carlos Garcia Gual (pp. 233-246). Zaragoza: Pórtico.

Cousland, J. R. C. y Hume, J. R. (Eds.) (2009). The play of Texts and Fragments. Essays in honour to Martin Cropp. Leiden: Brill.

Dunn, F. (1996). Tragedy's End. Closure and Innovation in Euripidean Drama. Oxford, New York: OUP.

Ebbott, M. (2017). Hippolytus. En L. McClure (Ed.), A Companion to Euripides (pp. 107-121). Oxford: Wiley Blackwell.

Gambon, L. (2009). La institución imaginaria del oikos en la tragedia de Euripides. Bahía Blanca: Ediuns.

Gelli, E. (2004). Sophocle e il mito. Alcune considerazioni per la ricostruzione e la datazione della Fedra. Prometheus 30(3), 193-208.

Gibert, J. (1997). Euripides' Hippolytus Plays: Which Came First?. CQ, 47, 85-97.

Gregory, J. (Ed.) (2005). A Companion to Greek Tragedy. London: Blackwell Publishing.

Gregory, J. (2009). A father's curse in Euripides'Hippolytus. En J. R. C. Cousland y J. R. Hume (Eds.), The play of Text and Fragments. Essays in Honour of Martin Cropp (pp. 35-48). Leiden: Brill.

Halleran, M. R. (1991). Gamos and Destruction in Euripides' Hippolytos. TAPhA, 121, 109-121.

Hutchinson, G. O. (2004). Euripides' Other Hippolytus. ZPE, 149, 15-28.

Jouan, F. (1989-1990). Femmes ardentes et chastes héros chez Euripide. Sacris Erudiri, 31, 187-208.

Kearns, E. (1989). The Heroes of Attica, Bulletin Supplement 57. London: University of London.

Lucas, J. M. (1992). El motivo de Putifar en la tragedia griega. Epos, 8, 37-56.

Luppe, W. (1994). Die Hypothesis zum ersten Hippolytos (P.Mich. inv. 6222A). ZPE, 102, 23-39.

Luppe, W. (2004). Die Hypothesis zum ersten Hippolytos; ein Versuch der Zusammenführung des P.Mich inv. 6222A und des P.Oxy. LVIII 4640. En G. Bastianini \& A. Casanova (Eds.), Euripide e i papyri (pp. 87-96). Florence: Istituto Papirologico "G. Vitelli".

Luppe, W. (2005). Zu Daten und Reihenfolge der beiden Hippolytos-Dramen des Euripides. ZPE, 151, 11-14.

Magnani, M. (2004). P. Mich. inv. 6222A e P. Oxy. LXVIII 4640 c. II: alcune osservazioni sull'argomentum (?) del primo Ippolito euripideo. Eikasmós, 15, 227-240.

Markantonatos, A. (Ed.) (2020). Brill's Companion to Euripides. Leiden \& Boston: Brill.

McClure, L. (Ed.) (2017). A Companion to Euripides. Oxford: Wiley Blackwell.

Mills, S. (2002). Euripides' Hippolytus. London: Duckworth.

Mills, S. (2003). Sophocles' Aegeus and Phaedra. En A. H. Sommerstein (Ed.), Shards from Kolonos (pp. 219-232). Bari: Levante Editrice.

Parker, R. (2011). The Power and Nature of Heroes. En On Greek Religion (pp. 103-123). Ithaka, NY: Cornell University Press. 
Pirenne-Delforge, V. (1994). L'Aphrodite Grecque, Kernos Supplement 4. Athènes-Liege: Centre International d'Étude de la Religion Grecque Antique.

Rehm, R. (2020). Ritual in Euripides. En A. Markantonatos (Ed.), Brill's Companion to Euripides (pp. 821-840). Leiden- Boston: Brill.

Roisman, H. M. (1999). The Veiled Hippolytus and Phaedra. Hermes, 127, 397-409.

Seaford, R. (2009). Aitiologies of Cult in Euripides, A Response to Scott Scullion. En J. R. C. Cousland y J. R. Hume (Eds.), The play of Text and Fragments. Essays in Honour of Martin Cropp (pp. 219-234). Leiden: Brill.

Séchan, L. (1926). Études sur la tragédie grecque dans ses rapports avec la céramique. Paris: H. Champion.

Sommerstein, A. H. (Ed.) (2003). Shards from Kolonos: Studies in Sophoclean Fragments. Bari: Levante Editrice.

Sommerstein, A. H. (2005). Tragedy and Myth. En R. Bushnell (Ed.), A Companion to Tragedy (pp. 163-180). Malden, MA, Oxford: Blackwell Publishing.

Sommerstein, A. H. (2010). The Titles of Greek Drama. En The Tangled Ways of Zeus: And Other Studies in and around Greek Tragedy (pp. 11-29). Oxford, New York: OUP.

Sourvinou-Inwood, Ch. (2004). Tragedy and Athenian Religion. Lanhan, MD: Lexington Books.

Taplin, O. (2007). Pots \& Plays Interactions Between Tragedy and Greek Vase-painting of the Fourth Century B.C. Los Angeles: J. Paul Getty Publications.

Vernant, J.-P. y Vidal-Naquet, P. (1972). Mythe et tragédie en Grèce ancienne I. Paris: F. Maspero.

Webster, T. B. L. (1967). The Tragedies of Euripides. London: Methuen.

\section{Notas}

1 En el presente trabajo, las citas de Pausanias corresponden a la edición teubneriana de la Descripción de Grecia de F. Spiro; las citas de Eurípides, en el caso de la obra completa, a la edición oxoniense de J. Diggle y las citas de tragedia fragmentaria, en cambio, a la edición de R, Kannicht de los $\operatorname{Tr} G F$ (vol. V).

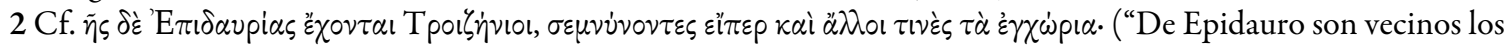
trecenios, que veneran más que otros las cosas de la propia tierra", Paus. 2.30.5). Si bien el culto de los héroes se distingue

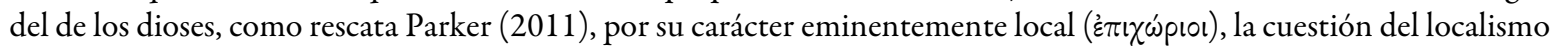
está vinculada al poder que ejercen estas figuras, un poder a menudo usado para legitimar reclamos territoriales o el privilegio o prestigio de una élite gobernante. Sobre Hipólito y los héroes áticos, cf. Kearns (1989).

3 Eurípides, en el citado fragmento de su tragedia perdida, utilizaba el propio término ñp $\omega \varsigma$ para referir a la figura de Hipólito, aunque no pueda probarse si el culto al que hace referencia allí es el ateniense o el trecenio: $\tilde{\omega} \mu \dot{\alpha} \alpha \alpha p$, oil $\alpha$

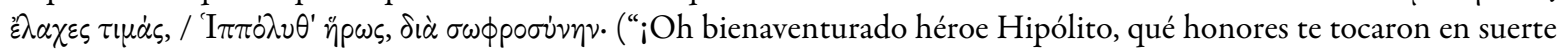
por tu prudencia!", E. fr. 446.1-2).

4 Cf. Barrett (1964, pp. 4-5); Kearns (1989, p. 173).

5 El santuario de Afrodita en Atenas, según recuerda Diodoro Sículo (4.62-2) estaba en el flanco sur de la Acrópolis "desde donde se puede ver Trecén", hecho que traduce la asimilación de la historia mítica de Atenas con la de aquel lugar. Sobre Afrodita, el santuario ático y el trecenio, cf. Pirenne-Delforge (1994, pp. 40-45; 178-181).

6 Nos referimos al poema épico Naupactias (s. VI a.C.), que aludía a la muerte de Hipólito y su resurrección por parte de Asclepio, una versión que retoma la posterior tradición latina sobre el mito del héroe. En el caso del culto trecenio, Pausanias menciona una estatua de Asclepio hecha por Timoteo que, sin embargo, los lugareños afirmaban que era una imagen de Hipólito (Paus. 2.32). El templo ateniense a Asclepio, por su parte, fundado en el 420/19 a.C., estaba junto al monumento de Hipólito (IG II2.4961). El culto a Asclepio en Epidauro data de fines del s. VI a.C., en Atenas, de fines del s. V a.C., y en Trecén del s. IV a.C.

7 Los fragmentos de Fedra de Sófocles, incluidos en la edición de Barrett (1964, pp. 22-26) y editados por Radt ( $\operatorname{Tr} G F$ 4, 1999), son traducidos y discutidos en la edición de Sommerstein-Fitzpatrick y Talboy (2006, pp. 290-317), a cuyo estudio preliminar remitimos. Los de Hipólito I figuran también en la edición de Barrett (1964, pp. 18-22), y son discutidos por Halleran (1995, pp. 25-37) y Jouan y van Looy (2000, vol. 3); la edición canónica es la de Kannicht (2004, $\operatorname{Tr} G F \mathrm{~V})$, y más recientemente, con traducción al inglés, han sido editados por Collard y Cropp (2008). Sobre la datación de los tres dramas, cf. Sommerstein-Fitzpatrick y Talboy (2006, pp. 287-289). Aunque no se conoce la fecha de la Fedra de Sófocles, y la ubicación de esta última entre Hipólito I e Hipólito II deba considerarse mera conjetura, ya 
autores como Séchan (1926) la daban por cierta (p. 323). Una presunción escéptica sobre la datación de Hipólito I con relación a la segunda versión supérstite ya fue planteada por Gibert (1997).

8 Cf. Bañuls, J. V.y P. Crespo (2008). De la obra Fedra de Sófocles contamos con menos de treinta versos distribuidos en apenas una veintena de fragmentos. Sobre los riesgos de la interpretación y reconstrucción de la obra de Sófocles en base a las de Eurípides ya advertía Mills (2003). Aunque no hay evidencia directa sobre la instauración del culto del héroe, Sommerstein y Talboy (Sommerstein-Fitzpatrick y Talboy, 2006, pp. 285-286) consideran plausible hipotetizar que para el final de su obra Sófocles adoptase la versión del mito que preveía la resurrección de Hipólito por intervención de Asclepio; dicha intervención, basada en su carácter heroico (no divino), requeriría la aparición de Apolo como deus ex machina.

9 "The bull coming from the sea is topograhically appropiate at Trozen" (Barrett, 1964, p. 7). El origen mítico de Trecén está vinculado a Piteo, que unificó las antiguas ciudades de Hiperea y Antea, nombrándola Trecén en honor a su hermano muerto (Paus. 2.30.9).

10 Séneca (Fedra) y Ovidio (Met. 15.497-546; Fast. 6.739) ambientan la historia de Fedra e Hipólito en Atenas, según opina Barrett (1964, p. 32) siguiendo la tradición épica vinculada a la figura de Teseo como rey de Atenas. En cuanto al

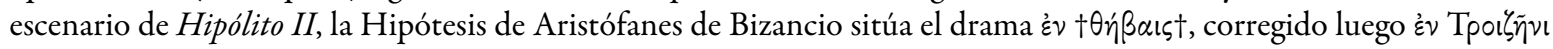
(ca. 1550), una corrección aceptada por los editores, bien que para Barrett no deja de mostrar inconsistencias.

11 Aunque muchos de los autores que se ocuparon inicialmente de los fragmentos de Hipólito I consideraron que, a diferencia de la segunda versión, la primera transcurriría en Atenas (e.g. W. Barrett, T.L.B. Webster, G. Danek), el Papiro de Michigan 6222A (s. II/III d.C.) vino a proponer, ya en la reconstrucción de W. Luppe, la localización de Trecén también para Hipólito I. Al respecto, cf. Luppe (1994; 2004; 2005). Sin embargo, el Pap. Oxy. 4620 (c. II d.C., test. iia), coincidente en varios términos con el anterior, pero donde no figura el nombre de Trecén, introdujo nuevos problemas vinculados a la reconstrucción de la trama dramática y a la explicación del apelativo que acompaña el nombre del héroe en el título. Al respecto, cf. las discusiones en Hutchinson (2004); Magnani (2004); Luppe (2005). Para Gelli (2004), las fuentes romanas se habrían inspirado en Fedra de Sófocles, tragedia ambientada claramente en Atenas. De la misma opinión son Talboy y Sommerstein (Sommerstein-Fitzpatrick y Talboy, 2006, p. 27), quienes dan por cierta la localización de los Hipólito ( $I$ y $I I)$ en Trecén.

12 Cf. Gambon (2009, p. 114). Sobre este punto, ver también Ebbott (2017).

13 Resulta significativa, así, la identidad múltiple que evoca Afrodita en el prólogo de la tragedia supérstite (E. Hipp., vv. 10-11).

14 Es decir, en el hecho de determinar, a partir de la presencia circunstancial de Fedra en Trecén, la convivencia con su hijastro en el mismo espacio. Esta situación, sumada, además, a la ausencia de Teseo, alimenta la amenaza de la pasión de

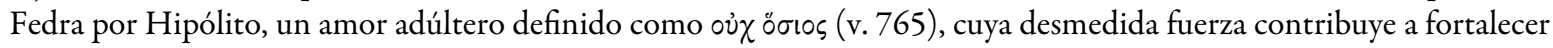
tanto la cercanía espacial como la debilitada condición de Fedra.

15 Pace Barrett (1964, p. 334), quien argumenta que la doble paternidad de Teseo surge únicamente de la conjunción de la tradición trecenia, y la ática. Gregory (2009) considera el tema de la maldición en Hipólito una innovación respecto de la primera versión, destinada precisamente a desplazar la responsabilidad de Teseo, reafirmando en cambio la del dios Poseidón, abuelo de Hipólito.

16 Sobre el motivo en Eurípides, cf. Jouan (1989-1990) y Lucas (1992).

17 “¡Oh confines ilustres de Atenas y de Palas, de qué suerte de hombre se verán privados!”. El v. 1459 es un verso considerado sospechoso por la crítica, y para el que Barrett mismo (1964, p. 416) reconoce no hallar una enmendación posible fuera del sentido general en que Atenas subsume a Trecén.

18 En tal sentido, y aunque no se indica el nombre de la Amazona en Hipólito (II), resulta revelador que los epítetos de la madre sean i $\pi \pi i \alpha$ (v. 307) y $\phi i \lambda \iota \pi \pi \circ \varsigma$ (v. 581).

19 El caballo es uno de los animales (sino el animal) especialmente ligado a Poseidón. El culto a Poseidón Hippios estaba muy extendido en Grecia y las carreras de carros eran una manera de honrarlo (Burkert, 2007, pp. 186-189). En la mitología el otro animal vinculado a Poseidón que juega un rol significativo en las historias de Fedra y de Hipólito es el toro.

$20 \mathrm{Y}$ de hecho, esta asociación se transfiere a la iconografía, que solo conoce representaciones de la escena del mensajero posteriores a Eurípides (cf. Taplin, 2007, pp. 135-138). En los siete testimonios referenciados por Taplin, los caballos y el toro son elementos comunes; dos de ellos incluyen en el plano divino la representación de Poseidón, divinidad que logra una presencia en la iconografía que no tiene, en cambio, Ártemis.

21 El origen de este título, a la luz de las hipótesis papiráceas del drama perdido a las que ya hicimos referencia, ha dado lugar a discutidas conjeturas. Una visión sumaria y una nueva lectura en Casanova (2014).

22 Gibert (1997) considera que el epíteto sería un añadido probablemente post-aristotélico o posteriores a las Didaskaliai (no figuraría en los registros que Aristóteles transcribe), lo que no permite argumentar en torno a la fecha anterior de uno u otro Hipólito. Sommerstein (2010) plantea que títulos como estos son helenísticos, aunque correspondientes a un período en que la obra estaba presente para los espectadores no como texto literario, sino como espectáculo. 
23 "In spite of the hatred of Aphrodite that Euripides ascribes to Hippolytus, he seems to have had a much stronger connection in cult with her than with Artemis" (Mills, 2002, p. 27).

24 Cf. Dunn (1996, pp. 87-100). Dunn subraya que este esquema de repetición construye la impresión de que la obra comienza con el final, y su éxodo constituye un comienzo, volviendo en tal sentido a ambas divinidades entre sí intercambiables.

25 Pace Halleran (2001, p. xxv), quien da por segura la aparición de Ártemis como dea ex machina al final de Hipólito I, sobre la base del fr. 446: "The four-line choral tag that survives, referring to Hippolytus' future cult, allows one to infer that the play conformed to many other Euripidean dramas in having a divinity who appeared on high and who, among other thing, predicted Hippolytus' future cult. The most likely candidate for this role is Artemis, Hippolytus' patron”. El citado fragmento pertenece a un canto final del Coro que, probablemente, bajo la forma de un makarismós refería a los honores consagrados al héroe tras su muerte. Ya Webster (1967) señalaba que este éxodo incluía una explicación etiológica al culto de Hipólito, y conjeturas como las de Jouan y van Looy (2000) suponen la aparición de un deus ex machina para prescribir el culto al héroe, aunque se ha hipotetizado también que pudiera corresponder a la resurrección de Hipólito por parte de Asclepio.

26 "Though this tragedy's ritual density is significant, it is not as great as that of some others; but the place of ritual in it is very important; ritual and other religious elements form the skeleton of the play (...)" (Sourvinou-Inwood, 2004, p. 332).

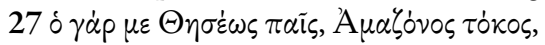

$\mathrm{I} \pi \pi \dot{\partial} \lambda \nu \tau \circ \varsigma, \dot{\alpha} \gamma \nu \sigma \tilde{\mathrm{U}} \Pi 1 \tau \theta \dot{\varepsilon} \omega \varsigma \pi \alpha 1 \delta \varepsilon \dot{\nu} \mu \alpha \tau \alpha$,

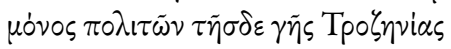

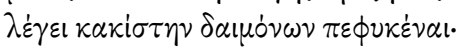

("El hijo de Teseo, vástago de la Amazona, discípulo del santo Piteo, es el único de los ciudadanos de Trecén que dice que soy la peor de las divinidades", E. Hipp., vv. 10-13).

28 Tal como ha sido señalado, y remarca Dunn (1996, p. 89), esta presencia de una etiología en el prólogo es tan extraña que ha dado fundamento a la teoría de la interpolación textual.

29 Así, el himno a Ártemis (vv. 58-71) sigue a la epifanía de Afrodita en el prólogo de la tragedia, y el himno a Afrodita y Eros en el cuarto estásimo (vv. 1268-1282) precede la epifanía de Ártemis. En cuanto a las estatuas y altares, en esta tragedia los editores y comentadores acuerdan en general en reconocer que junto a la fachada del palacio de Trecén se encontrarían las estatuas de Afrodita y Ártemis simétricamente dispuestas. Hay indicaciones claras de la posición de la imagen de la primera divinidad (cf. v. 101), pero no puede inferirse de ningún pasaje la posición de la estatua de Ártemis. No obstante, incluso Barrett (1964, p. 154 y n. ad vv. 82-83), a pesar de sus objeciones, acepta su presencia y la de un altar de la diosa en escena.

30 Sourvinou-Inwood (2004, pp. 327-328) pone de relieve que, a través de estas evocaciones rituales, Hipólito construye una imagen de la diosa que excluye una importante faceta suya, especialmente relevante en Atenas y que se relaciona con Afrodita, la de su vinculación con los rituales de transición a la adultez femenina.

31 Sobre la negación de la etiología ritual en Eurípides como invención con fines literarios, cf. Seaford (2009), en refutación a la tesitura de S. Scullion. 